\title{
The application of virtual reality technology in museum exhibition - Take the Han Dynasty Haihunhou Ruins Museum in Nanchang as an example
}

\author{
Liu $\operatorname{Han}^{1}$ a , Yang $\mathrm{Cui}^{2} \mathrm{~b}^{*}$ \\ ${ }^{1}$ College of Arts/Jiangxi University of Finance and Economics, Nanchang, China \\ ${ }^{2}$ College of Arts/Jiangxi University of Finance and Economics, Nanchang, China
}

\begin{abstract}
The opening of the Haihunhou Relics Museum of The Han Dynasty in Nanchang showcases the largest, best-preserved and most abundant legal-marquis tombs of the Han Dynasty discovered in China, and exhibits the historical sites and precious cultural relics of the Han Dynasty in an undamaged manner. The tomb of Haihunhou reflects the splendid civilization of an era, which is of great significance to the study of Chinese politics, economy and culture in han Dynasty. The display of the Han Dynasty Haihunhou Ruins Museum in Nanchang also represents the display level of today's China. Nowadays, people are more and more interested in and want to visit ancient relics. However, it is difficult for traditional museums to display ancient relics and visitors cannot understand the historical stories behind them. With the development of contemporary science and technology and virtual reality technology, museum exhibits more tends to digital, intelligent technology, through the cultural relics of the display of virtual reality technology, brings to the sea faint principality of nanchang han dynasty ruins museum different presentation, more fully play of the museum's education value and historical responsibility.
\end{abstract}

\section{THE NECESSITY OF VIRTUAL REALITY TECHNOLOGY FOR MUSEUM DISPLAY DESIGN}

Virtual Reality, also known as "VR technology", refers to the use of computers to simulate the real world and create a scene similar to the existence or simulation of the real world. Users can feel the real feeling of being in the fictional world from visual, auditory, tactile and other aspects. Computer simulation is a three-dimensional environment, a kind of information technology that can experience the virtual world. The audience can not only feel the immersive verisimilitude experienced in the objective world, or the virtual scene that does not exist in reality, through the VIRTUAL reality system. And they can break through space, time, and other objective limitations to experience things that are out of reach in the real world. The application of virtual reality technology in museum display has a wide range of practical prospects and far-reaching effects.

The construction of modern museum takes education and promotion as an important goal, and contemporary museum also presents different colorful expressions with the intervention of virtual reality technology. VR technology, as the representative of virtual reality, penetrates into the field of museum culture presentation and is an indispensable part of museum construction. In 2009, the Digital Sculpture Project launched in Virginia has successfully extended virtual reality technology into the field of cultural relic restoration, and proved the feasibility of the application of virtual reality technology in the field of museum heritage. In recent years, the application of virtual reality in museum furnishings and cultural heritage has been developing continuously, and there are quite successful examples.

The China Pavilion at the 2010 Shanghai World Expo has a 128-meter-long, 6.5-meter-high dynamic version of riverside Scene at Qingming Festival. Broadcasting with virtual reality technology presents the northern song dynasty information from henan bian city prosperous scene, originally static characters in the picture with the blessing of scene by virtual reality technology, will be more than 1000 period of northern song dynasty ancient characters and vivid image of the city landscape dynamic, alternately in day night, the actions of the characters vivid, full of drama. The dynamic version of Riverside Scene at Qingming Festival is deeply loved by the audience and has become one of the most popular exhibition items in the China Pavilion. It gives many visitors an immersive experience and leaves them with a lingering aftertaste. The exhibition was awarded the Best Live and experience event of the year 2011 by the British Visual Communication Association International.

Dynamic version of the qingming festival on the painting "of the virtual reality technology is embodied in the following aspects, first, a dynamic version of the qingming festival on the painting" in compliance with the original, on the basis of equal proportion amplifier 20 times, generated by means of the virtual reality

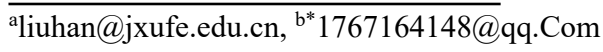


technology and real images rendered in a virtual scene environment is extremely similar, make originally small space to multi-level amplifier, get better rich details. When the audience sees the rectangular picture, the static picture is presented in the imagination of the brain with animation. "Walking beside the picture is like walking in the middle of a picture", which integrates the scene in the picture with the real audience, showing the incisively and vividly the sense of historical travel and immersion. Secondly, the dynamic version of riverside Scene at Qingming Festival USES film special effects, THREEDIMENSIONAL imaging, and other virtual reality technology means, using 12 projectors to project the dynamic picture on the screen, and the placement of the screen has also been cleverly designed, the large screen pleated. In order to avoid the visual discomfort caused by looking directly at the large screen, the pleated giant screen is the main visual manifestation form of virtual reality technology. The conversion imaging of multiple imaging devices and various digital technologies is the finishing touch to better present the Riverside Scene at Qingming Festival, one of the top 10 Famous Chinese paintings, to the audience. Finally, the dynamic version of Riverside Scene at Qingming Festival not only USES reasonable and appropriate expression techniques, but also presents the people's life and urban characteristics of the Northern Song Dynasty from different visual, auditory and sensory dimensions, infuses virtual reality technology with more artistic conception and atmosphere, and reflects the exhibition principle that the display form serves the exhibition content. It accurately shows the artistic conception of the original work. The dynamic version of Riverside Scene at Qingming Festival integrates art, technology and creativity into one. It has become a classic work of virtual reality application in cultural exhibitions.

"Innovation is the first driving force to lead the war" virtual reality technology, as a new expression of the display of cultural relics and historical narration in modern museums, can make ancient historical civilizations show modern vitality by combining virtual reality technology with museum display innovatively. The audience can enjoy the immersive experience brought by the visit, and learn the historical stories and times culture behind the cultural relics while visiting. Through the application of virtual reality technology in museum display and exhibition work, it has become a new form of museum display to display cultural relics to the public in all aspects and in multiple dimensions with the help of virtual reality technology, which is also under the background of modern science and technology development. The museum shows new ways of exploring in keeping with The Times.

\section{DISCUSSION ON THE APPLICATION OF VIRTUAL REALITY TECHNOLOGY IN DISPLAY DESIGN OF HAN DYNASTY HAIHUNHOU RUINS MUSEUM IN NANCHANG}

\subsection{Discussion on the feasibility of digitalization of exhibition design for Han Dynasty Haihunhou Ruins Museum in Nanchang}

In 2011, the ruins of the Han Dynasty Haihun Hou State in Nanchang were discovered, which is the most complete preserved cemetery of the Western Han Dynasty. The archaeological excavation of haihunhou tomb site lasted for five years, which revealed the most abundant han Dynasty hou settlement site in front of the world. The excavation of the ancient tomb of Haihunhou has unique historical and cultural value. The site of Haihunhou of the Han Dynasty in Nanchang has won several heavyweight awards in Chinese archaeology, such as "Six New Discoveries in Chinese Archaeology" by the Chinese Academy of Social Sciences and "Top Ten New Discoveries in China" by the State Administration of Cultural Heritage in 2015. The Haihunhou Ruins Park of the Han Dynasty in Nanchang was officially opened on September 23, 2020, displaying more than 1,200 cultural relics unearthed from the Haihunhou Ruins.

The haihunhou Ruins Museum of the Han Dynasty in Nanchang has a huge construction area with a total construction area of 39,330 square meters. In terms of functional area, it is divided into seven sections, including exhibition, cultural relics storage and cultural exchange. On the construction layer of the museum, in addition to the exhibition of displayed cultural relics, interactive facilities such as 4D cinema, Confucius School and other supporting projects are also set up. These projects are presented in a digital way.

Modern museums exhibit cultural relics and historic sites to the public. The unreproducibility of historical scenes, stories and pictures of cultural relics is the biggest obstacle for museums to show their history to the public. The traditional museum displays historical scenes mostly in the form of written materials and pictures, and later in the form of documentaries. However, visitors cannot get into the history, experience the stories behind cultural relics, or gain immersive and immersive feelings. With the development of modern science and technology, virtual reality technology has gradually entered the public vision and been widely used. It also provides a new way for museums to display their exhibits. In this context, the digitalization of the exhibition design of The Han Dynasty Haihunhou Ruins Museum in Nanchang is feasible and inevitable. There are mainly the following reasons: 1. As a first-class museum construction example in China, The Haihunhou Ruins Museum of the Han Dynasty in Nanchang should also reflect the national first-class museum construction level in terms of its perfection and advancement. Construction began in 2017 with the aim of preserving national treasures. Many cultural relics unearthed in the ancient tomb of Haihunhou, such as gold piles, sacred animals and jade pendants, were rated as the 
"top ten world treasures", which made the cultural relics exhibited in the Haihunhou Ruins Museum attract the attention of the world. In this way, the use of advanced science and technology and exhibition technology can better reflect the cultural relics of their own value 2, different from the traditional way of exhibition, innovative methods. According to statistics by the end of 2018, there were 5,354 museums in China. However, in terms of the display mode of cultural relics, the existing exhibition mode of museums tends to be "simplified". In the era of rapid development of information technology, the simple way of presentation appears traditional and rigid, which is not conducive to the long-term cultural inheritance and modern development needs. Therefore, nanchang Haihunhou Ruins Museum of the Han Dynasty should keep pace with The Times, make innovations, and have the courage to try the latest digital science and technology. In addition, the application of virtual reality technology is also a concrete manifestation of the new means of comprehensive application in museum display. 3. Virtual reality technology has been applied in a wide range of fields and its performance is becoming increasingly perfect. Digital and modern museums meet the needs of The Times and meet the viewing needs of different audiences under the fast-paced life. In addition, Chinese museums have also begun to introduce virtual reality technology to update the presentation mode. Therefore, the integration of digital museum and virtual reality technology in presentation mode is the only way for the long-term development of contemporary museum. The establishment of VR museum enables the audience to have an immersive feeling, which is an essential difference from the traditional museum in terms of senses. 4. The state supports the construction of museums. As cultural self-improvement and cultural confidence have gained popularity, more and more people have come to museums to learn about China's outstanding historical civilization. The notice issued by the State Administration of Cultural Heritage and the Ministry of Education in 2001 on strengthening the construction and development of university museums indicates that it supports the construction and development of museums, and also puts forward that the construction and development of museums have positive significance and important role for university education.

\subsection{Experience analysis of Virtual Reality technology in Han Dynasty Haihunhou Ruins Museum in Nanchang}

User experience, as a comprehensive feeling to measure the audience's emotional, physiological, psychological and other factors during the visit, has to be abandoned in the construction of the museum to carry out exhibition design. An important measure of a modern museum is user experience analysis. At present, many museums have successfully demonstrated the application of virtual reality technology in the design of museum exhibits. As the main role of museums is cultural communication, and the audience's thirst for knowledge is increasingly high, how to play the role of virtual reality technology in the display of cultural relics in The Han Dynasty Haihunhou Ruins Museum in Nanchang needs to be analyzed from the following aspects. The first is sensory experience. At present, "Golden Haihun -- Historical and Cultural Exhibition of Haihun State of Han Dynasty" in The Museum of The Ruins of Haihun State adopts the main colors of "yellow" of rammed earth, "red" and "black" of lacquer, and adopts theme-style design technique in the exhibition technique, and USES the grand and magnificent scene of rites and music to highlight the huge and magnificent carriage of horses and chariots. And the virtual reality technology of " $3 \mathrm{~d}$ animation" is used to explain the tomb structure of Haihunhou. The part of "Transparent screen + display cabinet" further enhances the user's sensory experience, and intuitively understands the structure and usage of the digester from visual and auditory aspects. Through the combination of immersive 3D screen and stage lighting, the audience can also roam the City of Purple and Gold in 3D, and experience the "Building the City of Purple and Gold" with touch screen. Part of golden Haihun is the initial exploration of the virtual reality technology applied by the Han Dynasty Haihun Hou Ruins Museum in Nanchang. It not only tells the history of the Western Han Dynasty comprehensively, but also brings different experiences to the audience. The second is user interaction experience. The interactive experience of the design and setting of the digital museum exhibition will increase the audience's recognition of the museum. When visitors visit the museum, visitors can browse, click, input, output and other operations on interactive devices in the process of user interaction experience, which can increase users' interactive experience. At the same time, we can have a deeper understanding of the content and cultural heritage of the exhibition hall.

\section{THE REALISTIC SIGNIFICANCE OF VIRTUAL REALITY TECHNOLOGY IN DISPLAY DESIGN OF HAN DYNASTY HAIHUNHOU RUINS MUSEUM IN NANCHANG}

\subsection{Reproduce the value of history}

The excavation of the tomb of Haihunhou filled the blank of the archaeological system of the burial system of the marquis of The Western Han Dynasty. The tomb of Haihun Marquis in Nanchang of the Western Han Dynasty is a typical representative of the marquis of the Western Han Dynasty, which has high research and historical value. In recent years, China has paid more attention to and strengthened the protection of cultural relics and historic sites. From the inheritance of historical civilization to the innovation of scientific and technological techniques, it is not only conducive to the protection of haihunhou culture, but also to the exhibition of precious ancient civilization in the eyes of modern people. The application of virtual reality technology in The Haihunhou Ruins Museum of the Han Dynasty in Nanchang is the main process of creatively applying the 
cutting-edge achievements of information technology to the reproduction of cultural relics. It is not only in the display of cultural relics on the surface, but also in the digital reproduction of history and the modern inheritance of culture.

\subsection{The dissemination of the cultural connotation of Haihunhou}

The Haihunhou Ruins Park of Han Dynasty is a new historical and cultural name card of Nanchang city. Haihunhou tomb, as the largest, best preserved and most abundant han Dynasty settlement site found in China, is the largest in China and has unique cultural connotation. Sea faint principality of nanchang han dynasty ruins museum in ZhanChen design how the sea faint hou to express the cultural connotation will need to use the advanced virtual reality technology, the faint hou cultural connotation of out of the museum into public view, makes out hou "speak" story, with the help of virtual reality technology for the further interaction with history of han dynasty civilization, showing the history of the western han dynasty prosperity brilliant culture, showing the history of nanchang massiness culture.

\section{ConClusion}

The application of virtual reality technology in the exhibition design of The Han Dynasty Haihunhou Ruins Museum in Nanchang is an important measure to integrate information technology and humanity, and constantly promote the development of digital museums by means of science and technology. The Haihunhou Ruins Museum of The Han Dynasty in Nanchang is an important carrier to present the civilization of the Han Dynasty. Virtual reality technology provides a new way of learning and viewing more directly, creates an immersive experience for the audience, and enables the audience to interact with the historical civilization in a more interesting way. With the continuous development of the technology, there will be more science and technology, the introduction of sea faint principality of nanchang han dynasty ruins museum ZhanChen design, for the digital museum culture dissemination and explanation of cultural relics to play a bigger role, at the same time the faint principality of nanchang han dynasty ruins museum museum exhibits protection and the drive of cultural heritage has important significance.

\section{REFERENCE}

1. liu, q. (2020) How does "cultural nostalgia" go to the world?-- On the Cultural Tourism and Foreign Translation of haihun Hou Ruins.Journal of Local Cultural Studies,pp.104-112.

2. Deng, Y, LEI, Q. (2017) Cultural Education in the Field of University museums. School of Mechanics. Beijing University of Aeronautics and Astronautics, 30(03), 116120DOI:
3. Huang, W.(2013) Current Situation and future of university museum in Jiangsu. Suzhou University Museum. Challenges and Opportunities,pp.105-108.

4. liao, W. (2020) Virtual reality technology and museum display. WenboBBS, pp: 92-94. 